\title{
Cation-exchange resins as heterogeneous catalysts for the synthesis of 1,3-butadiene from propylene and formaldehyde
}

\author{
T.M. Kutuzova, O.M. Kuznetzova, R.A. Akhmedyanova* \\ Kazan National Research Technological University, 420015 Karl Marx St., 72, Kazan, Russia \\ * Corresponding author: achra108@rambler.ru
}

This article belongs to the regular issue.

(C) 2021, The Authors. This article is published in open access form under the terms and conditions of the Creative Commons Attribution (CC BY) license (http://creativecommons.org/licenses/by/4.0/).

\section{Abstract}
The possibility of using the cation-exchange resin Lewatit K2420 as a catalyst for the synthesis of 1,3-butadiene from isopropyl alcohol and formaldehyde solution in one technological stage has been shown. The regularities of the process have been established and the influ- ence of the formaldehyde form (a cyclic trimer 1,3,5-trioxane and a $37 \%$ solution in water) on the composition of the reaction mass and the yield of the main and by-products has been assessed. It has been shown that the Lewatit K2420 heterogeneous catalyst showed cata- lytic activity in all reactions occurring in the synthesis of 1,3-butadiene, including the decomposition of 1,3,5-trioxane, dehy- dration of isopropyl alcohol into propylene, condensation of propyl- ene and formaldehyde, dehydration of 3-butene-1-ol, decomposition of 4-methyl-1,3-dioxane, etc.

\section{Keywords}

1,3-butadiene

cation exchange resin

formaldehyde

propylene

monomer

petrochemical synthesis

Received: 23.12.2020

Revised: 13.04.2021

Accepted: 20.04.2021

Available online: 28.04 .2021

\section{Introduction}

Among the processes based on the acid-catalyzed interaction of formaldehyde (FA) with iso-olefins the synthesis of isoprene from FA and isobutylene could be named, which is one of the main methods of isoprene production in Russia. Sulfuric, phosphoric, and oxalic acids are used as a catalyst in this process.

The current trend in improving the chemical technology processes is the replacement of homogeneous catalysts with heterogeneous ones. For acidic catalysts, such alternative is cation-exchange resins that meet all the requirements for catalytic systems (high activity, selectivity, dynamic stability and lifetime), while having a number of advantages over homogeneous catalysts, such as low corrosion activity towards equipment, no need to neutralize the catalyst after the synthesis completion, the possibility of multiple use of the catalyst without a significant decrease in its catalytic activity.

The works [1-3] describe methods for producing isoprene from trimethyl carbinol and isobutylene sources in the presence of cation-exchange resins (CER) and show the efficiency of their use as acid catalysts for these reactions.

The principal possibility of synthesizing the second most large-tonnage diene monomer, 1,3-butadiene (BD), from propylene (P) and FA by the Prins reaction was shown in work [4] in 1946. The process was two-step with the use of sulfuric acid acting as a catalyst on the first step.

Recently, publications have appeared on synthetic methods for the obtaining of $\mathrm{BD}$, for example, from ethanol [5]. These processes mainly use solid-phase catalysts containing a metal (silver, gold or copper) and a metal oxide (magnesium, titanium, zirconium, tantalum or niobium oxide), operating at a temperature of $200-400{ }^{\circ} \mathrm{C}$ and at least a three-fold excess of alcohol.

The relevance of the development of a new energyefficient, sophisticated process based on the use of modern achievements of chemical science and technology, led us to study the regularities of BD synthesis from isopropyl alcohol (IPA) (propylene) and FA in the presence of CER - heterogeneous acid catalysts that allow reactions to proceed under mild conditions and are not corrosive.

\section{Experimental}

The following materials were used in the research: isopropyl alcohol, melting temperature $-89.5{ }^{\circ} \mathrm{C}$, boiling temperature $\left.82.4{ }^{\circ} \mathrm{C}, \mathrm{d}_{4}{ }^{20}=0.7855 \mathrm{~g} / \mathrm{cm}^{3} ; \mathrm{n}_{\mathrm{D}}=1.3776\right)$; 1,3,5-trioxane (Acros Organics, 99+\%, melting temperature $61-62{ }^{\circ} \mathrm{C}$, boiling temperature $115{ }^{\circ} \mathrm{C}$ ); n-hexane, boil- 
ing temperature $68.74{ }^{\circ} \mathrm{C}$; crystallization temperature $95.32{ }^{\circ} \mathrm{C} ; \mathrm{d}_{4}{ }^{2 \mathrm{O}}==0.660 \mathrm{~g} / \mathrm{sm}^{3} ; \mathrm{n}_{\mathrm{D}}=1.3749$. The brands and characteristics of CER are presented in Table 1.

\subsection{Experimental procedures}

Calculated amounts of IPA, TO and CER were charged into stainless steel reactor-autoclave of $230 \mathrm{ml}$ (Berghof, Germany). The reactor was closed and placed into thermal protection case which placed on magnetic stirrer with heating. The reaction was carried out at a temperature of $150{ }^{\circ} \mathrm{C}$. The reaction time started, when a temperature in the reactor reached required value which was controlled by a thermocouple. The duration of experiments was from 1 to 4 hours.

\subsection{Analysis of products}

The composition of a reaction mass was identified on chromatograph Kristalyux 400oM with flame-ionization detector. The column was Supelco Analytical Petrocol DH (100 $\mathrm{m} \times 0.25 \mathrm{~mm} \times 0.5 \mu \mathrm{m}$ ); the carrier gas was helium. The temperature regime was as follows: constant temperature of $40{ }^{\circ} \mathrm{C}$ during $15 \mathrm{~min}$, then heating from 40 to $250^{\circ} \mathrm{C}$ with a rate of $5^{\circ} \mathrm{C} / \mathrm{min}$.

Composition and structure of reaction products were determined by chromatography-mass spectrometry using Agilent 5975 unit (column HP-5MS (5\%-Phenyl)methylpolysiloxane $30 \mathrm{~m} \times 0.25 \mathrm{~mm} \times 0.5 \mu \mathrm{m})$. Reference mass-spectra presented in database NIST11 were used to identify components. Component contents were calculated based on chromatographic peak areas on total ion current chromatogram without ionization efficiency correction [6].

\section{Results and Discussion}

The creation of macroporous CER with increased thermal stability and mechanical strength has opened up wide possibilities for their use in large-scale industrial technologies. Examples include the processes of obtaining methyl tert-butyl ether (MTBE), ethyl tert-butyl ether (ETBE), tert-amyl methyl ether (TAME), isobutylene separation from hydrocarbon $\mathrm{C}_{4}$ fractions, etc.

One of these catalysts is a macroporous sulfonic acid CER with a high exchange capacity Lewatit K2420, CER in the hydrogen form, the characteristics of which are presented in Table 1.

Table 1 Characteristics of the cation-exchange resin Lewatit K2420

\begin{tabular}{lll}
\hline Indicator & Units & Value \\
\hline Total exchange capacity & $\mathrm{mg} \mathrm{eq} / \mathrm{g}$ & 5.4 \\
eq/L & 1.4 \\
Granules effective size & $>90 \% \mathrm{~mm}$ & $0.5-1.6$ \\
Tap density & $( \pm 5 \%) \mathrm{g} / \mathrm{dm}^{3}$ & 740 \\
Pore volume & $\mathrm{cm}^{3} / \mathrm{g}$ & 0.40 \\
Average pore diameter & $\mathrm{nm}$ & 53 \\
\hline
\end{tabular}

The synthesis of BD from $\mathrm{P}$ and FA is based on the following consecutive chemical reactions:

$$
\begin{aligned}
& \mathrm{H}_{3} \mathrm{C}-\mathrm{CH}=\mathrm{CH}_{2}+\mathrm{H}_{2} \mathrm{C}=\mathrm{O} \stackrel{\left[\mathrm{H}^{+}\right]}{\longrightarrow} \\
& \stackrel{\left[\mathrm{H}^{+}\right]}{\longrightarrow} \mathrm{H}_{2} \mathrm{C}=\mathrm{CH}-\mathrm{CH}_{2}-\mathrm{CH}_{2}-\mathrm{OH} \frac{\left[\mathrm{H}^{+}\right]}{-\mathrm{H}_{2} \mathrm{O}}
\end{aligned}
$$

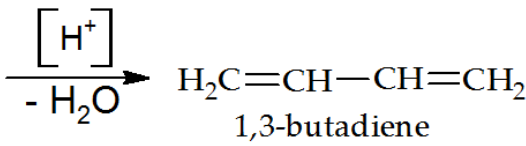

We have used IPA as a source of $\mathrm{P}$, which, under the conditions of synthesis in the presence of CER, very quickly dehydrates into P.

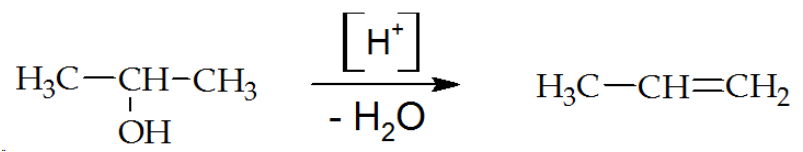

In the work [6], the results of studies on the P source, IPA, interaction with an anhydrous source of FA, 1,3,5-trioxane (TO), in the presence of Lewatit K2420 CER are presented. In the case of using concentrated forms of FA, the reaction leads to the formation of 3-butene-1-ol. Its subsequent intramolecular dehydration is accompanied by the release of the $\mathrm{BD}$ molecule. Among possible side reactions is the interaction of 3-butene-1-ol with a molecule of free FA with the formation of tetrahydropyranol (a BD precursor). The dehydration of the latter leads to the formation of dihydropyran (a BD precursor) (Scheme 1).

In this work, the $37 \%$ aqueous solution of $F A(F)$ is used as a source of FA. In this case, the reaction goes through the formation of butane-1,3-diol, the further interaction of which with a molecule of free FA leads to the formation of 4-methyl-1,3-dioxane, which traces are detected in the reaction mass. The decomposition of $4^{-}$ methyl-1,3-dioxane in the presence of CER under the conditions of synthesis releases the BD molecule, free FA, and water (Scheme 2).

Thus, the form of FA used to obtain $\mathrm{BD}$ via the reaction with $P$ in the presence of CER can have a noticeable effect on the reactions direction. Our studies have confirmed this assumption.

$$
\begin{aligned}
& \mathrm{H}_{3} \mathrm{C}-\mathrm{CH}=\mathrm{CH}_{2} \\
& \downarrow+\frac{\mathrm{H}_{2} \mathrm{C}=\mathrm{O}}{\left[\mathrm{H}^{+}\right]}
\end{aligned}
$$

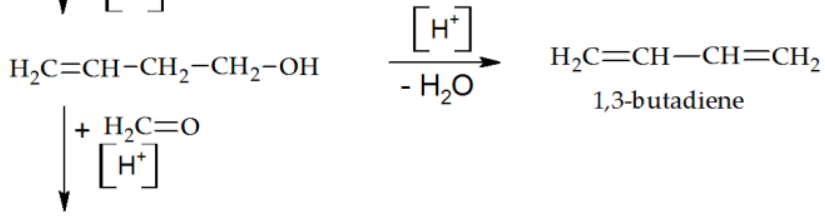

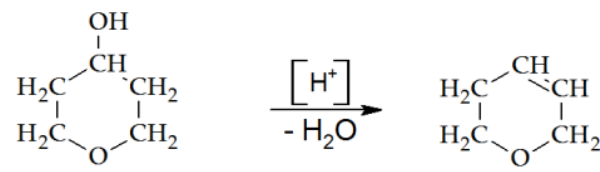

$$
\begin{aligned}
& \text { tetrahydro-2H-pyran-4-ol 3,6-dihydro-2H-pyran }
\end{aligned}
$$

Scheme 1 Reaction of $\mathrm{P}$ with FA in the form of TO 

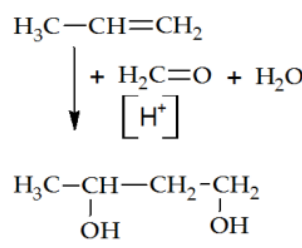

$$
\downarrow+\frac{\mathrm{H}_{2} \mathrm{C}=\mathrm{O}}{\left[\mathrm{H}^{+}\right]}
$$

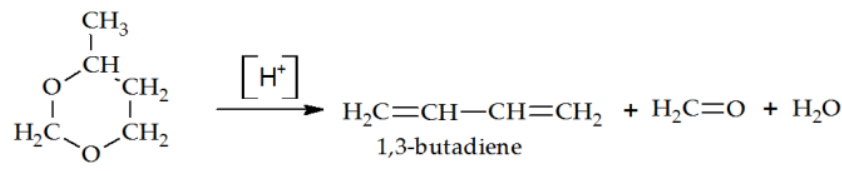

4-methyl-1,3-dioxane

Scheme 2 Reaction of P with FA in the form of $37 \%$ solution in water

In the process under study, CER is at the same time the catalyst for the decomposition of TO, the IPA dehydration to $\mathrm{P}$, the condensation of $\mathrm{P}$ with FA, and, finally, the dehydration of 3-butene-1-ol into BD or the decomposition of 4-methyl-1,3-dioxane.

Temperature is an important factor influencing the CER activity and selectivity.

The increase of temperature from 130 to $150{ }^{\circ} \mathrm{C}$ is followed by the increase of the $\mathrm{BD}$ yield and the yield of byproducts, including 3,6-dihydro-2H-pyran, 4-methyl-1,3dioxane and tetrahydro-2H-pyran-4-ol (Table 2).

When an aqueous solution $\mathrm{F}$ is used, the $\mathrm{BD}$ yield is $52 \%$ higher than that of TO. Moreover, the yield of byproducts is lower. Thus, the use of an aqueous solution $F$ leads to the increase in the $\mathrm{BD}$ selectivity. Despite the observed tendency for the target product yield to increase with the increase in the process temperature, the further increase in temperature is limited by the maximum possible operating temperature of CER.

The catalyst concentration (the content of sulfonic acid groups in the CER) has a significant effect on the yield of $\mathrm{BD}$ and by-products, regardless of the formaldehyde form (Fig. 1).

The DB yield is maximum at a concentration of $0.6 \mathrm{eq} / \mathrm{L}$. The decrease in the target product yield with the increase in the catalyst amount is due to the increase in side reactions, which is shown in Figs. 2-4.

Table 2 Main products yield obtained at BD synthesis from IPA and FA at different temperatures: $[\mathrm{FA}]:[\mathrm{IPA}]=1: 5 \mathrm{~mol}$;

\begin{tabular}{|c|c|c|c|c|c|c|c|c|}
\hline \multirow{3}{*}{$T,{ }^{\circ} \mathrm{C}$} & \multicolumn{8}{|c|}{ BD synthesis products yield, \% } \\
\hline & \multicolumn{2}{|c|}{$\begin{array}{l}1.3^{-} \\
\text {Butadiene }\end{array}$} & \multicolumn{2}{|c|}{$\begin{array}{l}\text { 3,6-dihydro- } \\
\text { 2H-pyran }\end{array}$} & \multicolumn{2}{|c|}{$\begin{array}{l}\text { 4-methyl- } \\
\text { 1,3-dioxane }\end{array}$} & \multicolumn{2}{|c|}{$\begin{array}{l}\text { Tetrahydro- } \\
2 \mathrm{H} \text {-pyran-4- } \\
\text { ol }\end{array}$} \\
\hline & TO & $\mathrm{F}$ & $\mathrm{TO}$ & $\mathrm{F}$ & TO & $\mathrm{F}$ & TO & $\mathrm{F}$ \\
\hline 130 & 1.26 & 1.18 & 0.10 & 1.79 & 0.01 & 1.10 & 0.05 & 1.91 \\
\hline 140 & 4.92 & 1.25 & 1.10 & 2.99 & 0.18 & 1.70 & 2.03 & 1.82 \\
\hline 150 & 6.45 & 9.83 & 6.33 & 4.14 & 0.01 & 0.01 & 7.01 & 3.19 \\
\hline
\end{tabular}
$\left[\mathrm{SO}_{3} \mathrm{H}\right]=0.6 \mathrm{eq} / \mathrm{L}, \tau=180 \mathrm{~min}$

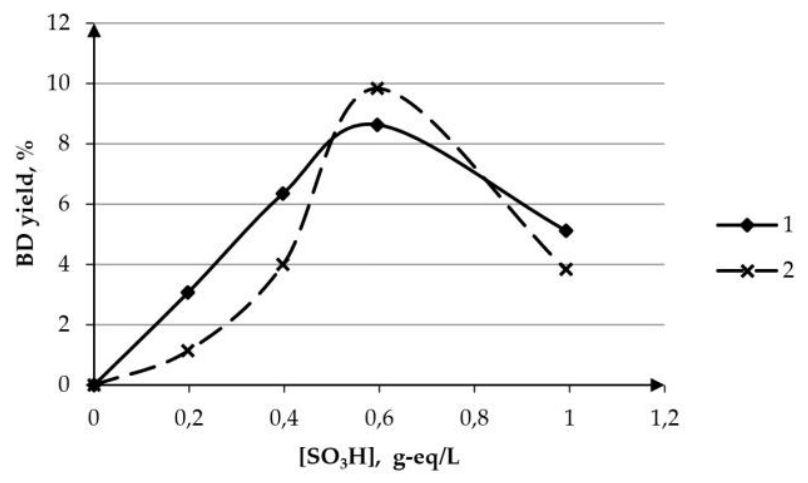

Fig. 1 Dependence of the butadiene yield on the $\mathrm{SO}_{3} \mathrm{H}$ groups concentration: $[\mathrm{FA}]:[\mathrm{IPA}]=1: 5 \mathrm{~mol}$; $\tau=18 \mathrm{omin} ; T=150{ }^{\circ} \mathrm{C}$, $1-$ TO, $2-37 \%$ aqueous solution of formaldehyde

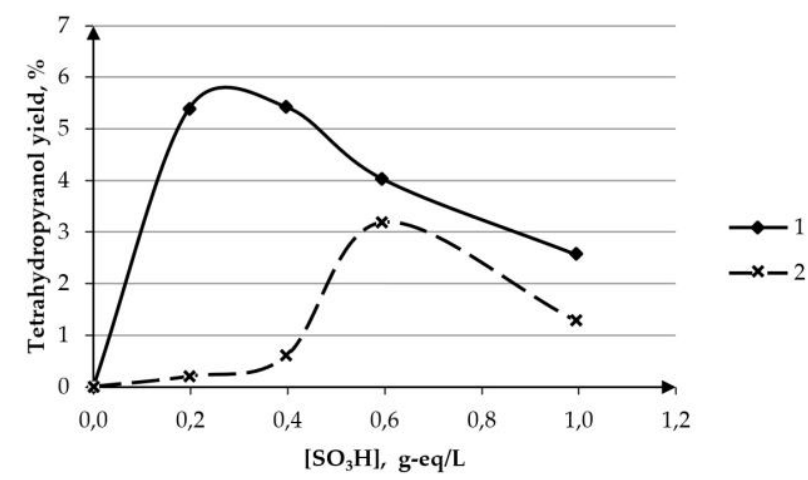

Fig. 2 Dependence of the tetrahydropyranol yield on the $\mathrm{SO}_{3} \mathrm{H}$ groups concentration: $[\mathrm{FA}]:[\mathrm{IPA}]=1: 5 \mathrm{~mol}$; $\tau=180 \mathrm{~min}$; $T=15 \mathrm{O}^{\circ} \mathrm{C}, 1-\mathrm{TO}, 2-37 \%$ aqueous solution of formaldehyde

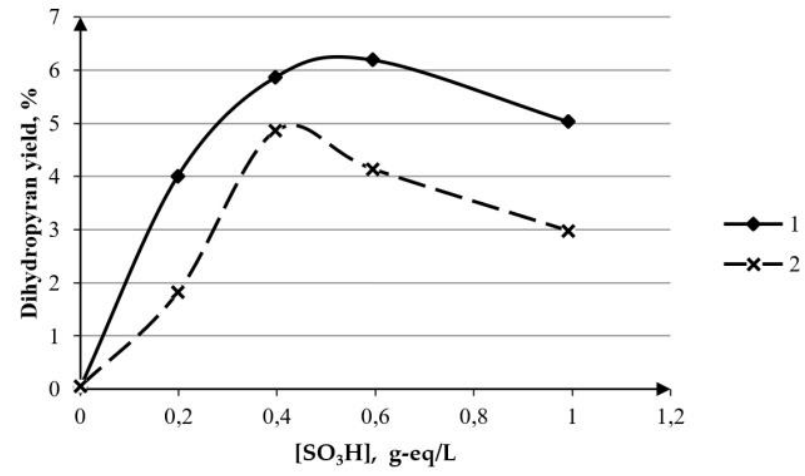

Fig. 3 Dependence of the dihydropyran yield on the $\mathrm{SO}_{3} \mathrm{H}$ groups concentration: $[\mathrm{FA}]:[\mathrm{IPA}]=1: 5 \mathrm{~mol}$.; $\tau=180 \mathrm{~min} ; T=150{ }^{\circ} \mathrm{C}$, 1 - TO, $2-37 \%$ aqueous solution of formaldehyde

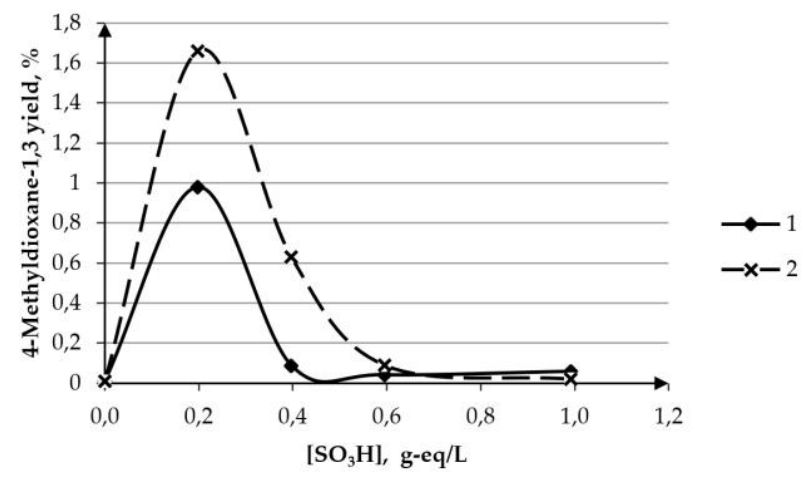

Fig. 4 Dependence of the methyldioxane yield on the $\mathrm{SO}_{3} \mathrm{H}$ groups concentration: $[\mathrm{FA}]:[\mathrm{IPA}]=1: 5 \mathrm{~mol}$; $\tau=18 \mathrm{o} \mathrm{min} ; T=15 \mathrm{O}^{\circ} \mathrm{C}$, $1-$ TO, $2-37 \%$ aqueous solution of formaldehyde 
The yield of tetrahydropyranol is high in the region of low concentrations of acid sites for syntheses with anhydrous formaldehyde (Fig. 2). The increase in the CER concentration in the reaction system leads to the decrease in the tetrahydropyranol yield, which is due to its conversion into BD and dihydropyran. When using an aqueous formaldehyde solution, the maximum tetrahydropyranol yield is observed at a concentration of $\mathrm{SO}_{3} \mathrm{H}$ groups equal to $0.6 \mathrm{eq} / \mathrm{L}$. This is due to the presence of water in the system, which leads to the hydrolysis reaction of dihydropyran with the formation of tetrahydropyranol. This is shown by the decrease in the dihydropyran yield at a concentration of $\mathrm{SO}_{3} \mathrm{H}$ groups of more than 0.6 eq/L (Fig. 3). Moreover, depending on the form of formaldehyde, the maximum dihydropyran yield is observed at different concentrations of $\mathrm{SO}_{3} \mathrm{H}$ groups.

The maximum methyldioxane yield is observed at low CER concentrations - $0.2 \mathrm{eq} / \mathrm{L}$ (Fig. 4). In this case, it is worth noting the higher MD content in the syntheses using $\mathrm{FA}$ in an aqueous solution, since in this case the reaction of obtaining BD goes mainly through the formation of MD, in contrast to the synthesis from anhydrous TO, when the reaction goes through the formation of 3-butene-1-ol. Therefore, in all syntheses using TO, a low MD content in the reaction medium is observed.

Increasing in the reaction time to 180 min leads to the increase in the BD yield. Further increase in the reaction time in a periodic mode demonstrates the decrease in $\mathrm{BD}$ yield (Fig. 5). At the same time, the dependences of the DB precursors (by-products) yield in this case have a different character for different formaldehyde forms (Table 3).

It is important to note that at higher temperatures, CER, as well as other acid catalysts, accelerates the oligomerization reactions of unsaturated compounds, in our case propylene and 1,3-butadiene. This leads to the decrease in the catalyst activity due to the formation of resins that block the access to the active sites, as well as to an unproductive loss of monomers. The longer unsaturated compounds are in direct contact with active sites, the greater is the probability of oligomerization reactions occurring. This problem can be solved by introducing an inert organic solvent, n-hexane, which dissolves propylene and butadiene and removes them from the contact zone with the acid sites of CER, into the reaction mixture. It is demonstrated by the increase of the BD yield with the increase in n-hexane concentration (Fig. 6).

Table 3 Yield of the BD synthesis products

\begin{tabular}{lllllll}
\hline \multirow{2}{*}{$\begin{array}{l}\text { Reaction } \\
\text { time, min }\end{array}$} & \multicolumn{2}{l}{$\begin{array}{l}\text { Y,6-dihydro- } \\
\text { 2H-pyran }\end{array}$} & $\begin{array}{l}\text { 4-methyl-1.3- } \\
\text { dioxane }\end{array}$ & $\begin{array}{l}\text { Tetrahydro- } \\
\text { 2H-pyran-4-ol }\end{array}$ \\
\cline { 2 - 7 } & TO & F & TO & F & TO & F \\
\hline 60 & 2.0 & 1.2 & 0.003 & 0.1 & 4.1 & 0.90 \\
120 & 6.5 & 2.49 & 0.004 & 0.06 & 7.00 & 1.99 \\
180 & 6.33 & 4.14 & 0.006 & 0.04 & 7.19 & 3.19 \\
240 & 8.49 & 3.49 & 0.038 & 0.03 & 11.27 & 2.00 \\
\hline
\end{tabular}

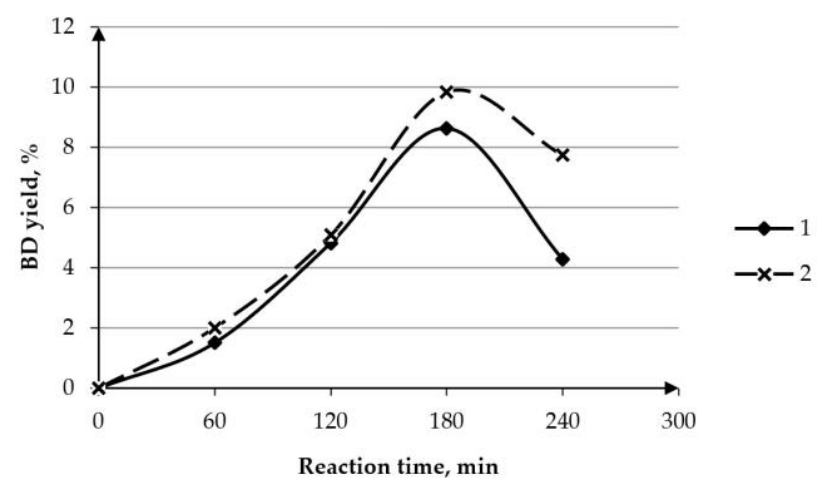

Fig. 5 Dependence of the BD yield on reaction time; [FA]:[IPA] = $1: 5 \mathrm{~mol}$; $\mathrm{T}=150{ }^{\circ} \mathrm{C},\left[\mathrm{SO}_{3} \mathrm{H}\right]=0.6 \mathrm{eq} / \mathrm{L}, 1-\mathrm{TO}, 2-37 \%$ aqueous solution of formaldehyde

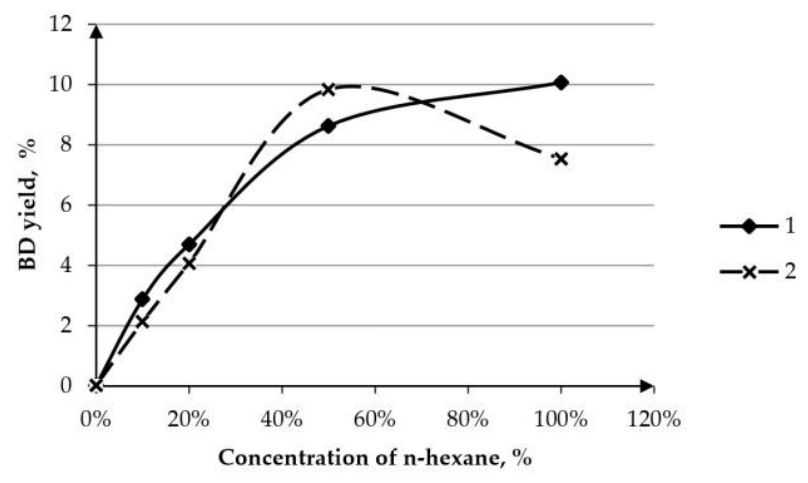

Fig. 6 Dependence of the BD yield on n-hexane concentration: [FA]:[IPA] $=1: 5 \mathrm{~mol}$.; $T=150^{\circ} \mathrm{C}, \tau=180 \mathrm{~min}, 1-\mathrm{TO}, 2-37 \%$ aqueous solution of formaldehyde

\section{Conclusions}

Thus, the regularities of the BD synthesis from IPA and an aqueous solution of FA in the presence of the Lewatit K2420 heterogeneous catalyst have been studied, and the influence of the FA, a cyclic trimer 1,3,5-trioxane and a $37 \%$ solution in water, form has been evaluated. The Lewatit K2420 heterogeneous catalyst has been shown to exhibit catalytic activity in all processes occurring in the DB synthesis, including decomposition of 1,3,5-trioxane, dehydration of isopropyl alcohol into propylene, condensation of propylene and formaldehyde, dehydration of 3-butene-1-ol, decomposition of 4-methyl-1,3-dioxane etc. The use of CER as a catalyst made it possible to carry out the reaction in one technological stage under mild conditions, without the threat of equipment corrosion. The possibility of reusing the catalyst has been studied, and the need for its regeneration has been shown, which is associated with the processes of undesirable oligomerization of unsaturated compounds, leading to the formation of resins that block the catalyst active centers.

The optimal conditions for the BD synthesis from IPA and FA were selected, providing the maximum yield of 1,3-butadiene of 9.83\%: [FA]: [IPA] = 1:5 mol.; $T=150{ }^{\circ} \mathrm{C}$; $\left[\mathrm{SO}_{3} \mathrm{H}\right]=0.6 \mathrm{eq} / \mathrm{L}, \tau=180 \mathrm{~min}$. 
It has been shown that the nature of the FA source affects the transformations mechanism; 2 possible routes of reactions occurring in the $\mathrm{BD}$ synthesis have been given.

\section{References}

1. Vavilov DI, Ahmedyanova RA, Liakumovich AG, Levin YaA. Sintez isoprena iz 1,3-dioxolanf and trimethilcarbinola $\mathrm{v}$ prisutstvii sulfocationoobmennyh smol [Synthesis of isoprene from 1,3-dioxolane and trimethylcarbinol in the presence of sulfonic cation exchange resins]. Russian Journal of Chemistry and Chemical Technology. 2011;54(5):113-6. Available from:

https://www.elibrary.ru/download/elibrary 163885166010 0076.pdf

2. Burkin KE, Akhmedyanova RA. Novel ecological and energy saving method of single-stage synthesis of isoprene novel ecological and energy saving method of single-stage synthesis of isoprene. Chemistry for sustainable development. 2011;19:531-5. Available from:

https://www.sibran.ru/upload/iblock/d1d/d1dodoodgba88d eo2aazedc4dff $43 f 6 f . p d f$
3. Burkin KE, Akhmedyanova RA, Liakumovich AG. Odnostadiynyy sintez izoprena iz 1,3,5-trioksana i trimetilkarbinola $\mathrm{v}$ prisutstvii kationoobmennykh smol [One-step synthesis of isoprene from 1,3,5-trioxane and trimethylcarbinol in the presence of cation exchange resins]. Industrial production and use of elastomers. 2011;2:11-4.

4. Workman AR, author; Cities Service Oil Co, assignee. Manufacture of butadiene from propene and formaldehyde. United States patent US 2412762A, 1947 December 17.

5. Ordomsky VV; Sushkevich VL.; Ivanova II, inventors; Limited Liability Company «UNISIT», assignee. Odnostadiynyy sposob polucheniya butadiyena [One-step method for producing butadiene]. Russian Federation patent RU 2440962C1. 2010 July 29. Russian.

6. Bogacheva TM, Zevakina AO, Akhmedyanova RA, Zenitova LA. Synthesis of butadiene-1,3 from isopropyl alcohol and trioxane. Processes of petrochemistry and oil refining 2018; 1 : 46-58. Available from:

http://ppor.az/jpdf/TatyanaBogacheva-1(2018).PDF 